\title{
References
}

SEDlock DA, LAventure SJ. Body composition and resting energy expenditure in long term spinal cord injury. Paraplegia 1990;28:448-454.

WADE OL, BISHOP JM. Cardiac output and regional blood flow. Oxford: Blackwell, 1962;p 93.

Cournand A, Richards DW. Trans Ass Amer Phys 1954;67:162.

SILVER JR. The oxygen cost of breathing in tetraplegic patients. Paraplegia 1963:204-214.

\author{
J. R. Silver \\ Consultant in Spinal Injuries \\ Stoke Mandeville Hospital \\ Aylesbury, UK
}

\section{Reply from Dr D. A. Sedlock}

Thank you for sharing with me and allowing me to reply to the letter sent to you from Dr J. R. Silver regarding our article entitled 'Body composition and resting energy expenditure in long term spinal cord injury' Paraplegia 1990;28:448-454.

Dr Silver provides some evidence ${ }^{1}$ to indicate that skeletal muscle accounts for a substantial proportion of resting oxygen uptake, and therefore disagrees with the statement in our article ${ }^{2}$ that a spinal lesion below $\mathrm{T} 10^{\prime} \ldots$. would affect predominantly lower extremity skeletal muscle, which contributes little to resting energy expenditure'.

Although the evidence cited by Dr Silver shows skeletal muscle to account for $30 \%$ of resting energy expenditure, ${ }^{1}$ Bray and Atkinson ${ }^{3}$ report previously published values ranging from $17-25 \%$. Regardless of the actual proportion, these percentages reflect the oxygen consumed by the skeletal musculature of the entire body. If we assume that the lower extremities account for even as much as $60 \%$ of the total body skeletal musculature, then it follows that 60 of the estimated $17-30 \%$ of skeletal muscle metabolism can be accounted for by this muscle mass. Therefore, the contribution of the lower body skeletal muscle to whole body resting oxygen uptake becomes $10-18 \%$.

If the organic tissue in the affected areas was completely silent (or absent, as in the case of amputees), one could expect resting metabolic rate to be reduced by the entire estimated $10-18 \%$. However, these areas contain active, respiring cells which are consuming oxygen, but probably at a reduced rate. That is, the sympathetic motor tone is absent. It is reasonable to speculate that the reduction in resting metabolic rate that would occur from a lesion below T10 would be considerably lower than the predicted 10-18\%.

Regarding the data from a study conducted by Dr Silver ${ }^{4}$ the subjects were tetraplegics with lesion levels ranging from C5-T3. It seems that with such high lesions the affected areas would include not only lower extremity skeletal muscle, but also the splanchnic and renal areas as well as the upper extremity and trunk musculature. According to Wade and Bishop, ${ }^{1}$ the splanchnic and renal areas together account for $32 \%$ of resting oxygen consumption. If one adds to this the relatively large proportion of affected skeletal muscle (upper body, trunk, and lower body), it is not surprising that Dr Silver found low metabolic rates in his study sample.

We contend that relatively low lesion levels (i.e., below approximately T10) should not have much of an effect on resting oxygen consumption. However, as the lesion level becomes higher, involving a greater quantity respiring tissue, one could expect increasingly greater reductions in resting metabolic rate.

\section{References}

1 WADE OL, BISHOP JM. Cardiac output and regional blood flow. Oxford: Blackwell, 1962.

2 SEDlock DA, LAventure SJ. Body composition and resting energy expenditure in long term spinal cord injury. Paraplegia 1990;128:448-454.

3 Bray GA, Atrinson RL. Factors affecting basal metabolic rate. Prog Fd Nutr Sci Vol. 2. Pergamon Press.

4 SILVER JR. The oxygen cost of breathing in tetraplegic patients. Paraplegia 1963:204-214.

D. A. Sedlock, PhD, FACSM

Associate Professor and Director Exercise Physiology Laboratories

West Lafayette, Indiana, USA 